\title{
Magnetics and Superconductivity Section Annual Progress Report for Period Ending December 31, 1976
}

\author{
M. S. Lubell \\ L. Dresner
}

\section{MASTER}




\section{DISCLAIMER}

This report was prepared as an account of work sponsored by an agency of the United States Government. Neither the United States Government nor any agency Thereof, nor any of their employees, makes any warranty, express or implied, or assumes any legal liability or responsibility for the accuracy, completeness, or usefulness of any information, apparatus, product, or process disclosed, or represents that its use would not infringe privately owned rights. Reference herein to any specific commercial product, process, or service by trade name, trademark, manufacturer, or otherwise does not necessarily constitute or imply its endorsement, recommendation, or favoring by the United States Government or any agency thereof. The views and opinions of authors expressed herein do not necessarily state or reflect those of the United States Government or any agency thereof. 


\section{DISCLAIMER}

Portions of this document may be illegible in electronic image products. Images are produced from the best available original document. 


\section{Printed in the United States of America. Available from}

National Technical Information Service

U.S. Department of Commerce

5285 Port Royal Road, Springfield, Virginia '2'2161

Price: Printed Copy $\$ 4.00 ;$ Microfiche $\$ 3.00$

This report was prepared as an account of work sponsored by the United States Government. Neither the United States nor the Energy Research and Development Administration/United States Nuclear Regulatory Commission, nor any of their employees, nor any of their contractors, subcontractors, or their employees, makes any warranty, express or implied, or assumes any legal liability or responsibility for the accuracy, completeness or usefulness of any information, apparatus, product or process disclosed, or represents that its use would not infringe privately owned rights. 
Contract No. W-7405-eng-26

Fusion Energy Division

MAGNETICS AND SUPERCONDUCTIVITY SECTION ANNUAL PROGRESS REPORT.

FOR PERIOD ENDING DECEMBER 31, 1976

Edited by

M. S. Lubell and L. Dresner

NOTICE

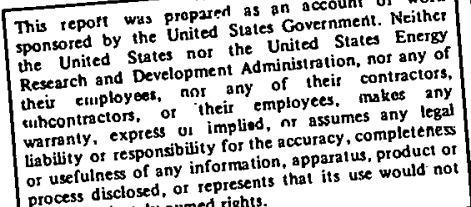

Date Published - June 1977

or
process disclosed, of represents

infringe privately owned rights.

Prepared by the

OAK RIDGE NATIONAL. LABORATUKY

Oak Ridge, Tennessee 37830

operated by

UNION CARBIDE CORPORATION

for the

ENERGY RESEARCH AND DEVELOPMENT ADMINISTRATION 


\section{THIS PAGE}

WAS INTENTIONALLY

\section{LEFT BLANK}


Abstract . . . . . . . . . . . . . . . . . . . . . . . . .

I. INTRODUCTION . . . . . . . . . . . . . . . . . . . . . . . . . . 1

1.1 DESIGN PROJECTS . . . . . . . . . . . . . . . . . . . . . . . . . . . 1

1.1 .1 EPR. . . . . . . . . . . . . . . . . . . . . . . . 1

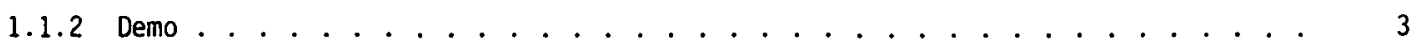

1.1 .3 TNS. . . . . . . . . . . . . . . . . . . . . . 3

1.1 .4 LCP. . . . . . . . . . . . . . . . . . . . . . . . 4

1.1 .5 EBTR............................... . . . . . . . 4

1.1 .6 EBT-II ............................. . . . . . 5

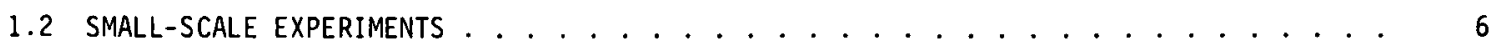

1.2.1 Pulsed Parallel Field. . . . . . . . . . . . . . . . . . . . 6

1.2.2 Propagation and Stability Tests. . . . . . . . . . . . . . . . 6

1.2.3 Conductor Design and Tests...................... 8

1.2 .4 Pulse (Poloidal) Coils......................... . . . . 9

1.2 .5 Instrumentation ........................ . . . 11

1.3 LARGE COIL EXPERIMENTS . . . . . . . . . . . . . . . . . . . . . . . . . . . 14

1.3.1 Large Coil Segment Test . . . . . . . . . . . . . . . . . . . . 14

1.4 PROJECTS BASED ON DISCIPLINES . . . . . . . . . . . . . . . . . . . . . . . . . . 14

1.4.1 Protection Analysis and Eddy Current Calculations. . . . . . . . . . . . . . 14

1.4.2 Structural Analysis and Material Tests . . . . . . . . . . . . . . . 17

1.4.3 Fabrication Development ..................... 20

1.5 PROJECTS REQUIRING WORK BY SUBCONTRACTORS . . . . . . . . . . . . . . . . . . . . 20

1.5.1 Forced-Cooled Magnets. . . . . . . . . . . . . . . . . . . . . 20

1.5.2 Helium Refrigerator and Handling System. . . . . . . . . . . . . . . . 21

1.6 VISITORS (OCTOBER 1 TO DECEMBER 31,1976 ) . . . . . . . . . . . . . . . . . . 21

1.7 STAFF TRIPS $($ OCTOBER 1 TO DECEMBER 31,1976$) . \ldots . . . . . . . . . . . .22$ 
THIS PAGE

\section{WAS INTENTIONALLY LEFT BLANK}


The Magnetics and Superconductivity Section has the responsibllity for developing superconducting magnet systems for tokamak fusion machines. This is being accomplished by carrying out those research and development needs which will provide the physics understanding and engineering data necessary to design, fabricate, and test large toroidal field (TF) and polotdal field (PF) colls. This information, in addition, supports the Large Coll Program (LCP).

A number of design projects have been performed, some in support of other programs and some of a continuing nature. These efforts support the goals and requirements for both the TF and PF magnet systems. Examples are the magnet designs for the EPR, Demo, EBTR, EBT-II, and preliminary scoping for the TNS project. The principal effort was expended on the iteration of the EPR Reference Design. Three features of the original reference design - the honeycomb coil structure, the oval coil shape, and the forced-flow cooling of the conductor by supercritical helium - remain as key features of the IF coils. Considerable progress has been made in the theoretical understanding of forced-flow-cooled conductors, and optimized designs with maximum stability margin can be designed to meet specific applications. Experiments which will test the theory are in progress.

A number of projects consisting of laboratory scale experiments, primarily to characterize conductor, are performed as needed. A new pulsed parallel fleld apparatus has been constructed to determine the losses that a conductor exhibits in the environment characteristic of a tokamak TF conductor, i.e., pulsed longitudinal field superimposed on a transverse field. Both propagation and stability experiments were performed for pool-bolling conductors and compared wt th as complete a theory as can presently be constructed; it was concluded that transient heat transfer effects are very important. These experimental results and theoretical calculations, along with mechanical tests on a wide variety of conductors, resulted in new designs being prepared for 10-kA, 8-T conductors. At year's end two pool-boiling conductors had been ordered. Another series of small-scale experiments was directed at obtaining informatinn relevant to the design of the PF coils. A pulse loss measurement system capable of providing the total energy loss and the loss voltage waveform for a pulsed (poloidal) coil was completed. The loss voltage was shown to be useful as a quench detection scheme for TF coils. Within the limits of the available power supplies, four small pulsed coils were tested and their losses characterlized. All the pulse coil work to date is focused on obtaining an economical and reliable conductor design which will attain the maximum field at the anticipated field rate of change with acceptable losses in a scalable, stable magnet design.

Design, procurement, and fabrication development have been initiated for the Large Coil Segment (LCS) tests. A 3-m winding facility with some new refinements has been set up near the superconducting laboratories and the site selected for LCS, and an oval bobbin has been procured for practice winding. In addition some specialized instrumentation has been developed and a data acquisition system designed for use in the LCS tests.

The two disciplines that involve analytical calculations to a large extent, magnet protection and structural analysis, have contributed in a significant manner to all the large machine designs and the, forthcoming large magnet tests. Examples of these developments are a new method for quench detection, complete analysis of the protection for a toroidal magnet system, development of a two-dimensional eddy current code applicable even if ferromagnetic material is present, and development of an analytical solution for the mechanical behavior of a transversely isotropic solenoid.

Procurement of facilities such as the large refrigerator, a liquid helium handling system, and power supplies for both the base research and development program and the LCP test facility has been initiated; these factlitios w1ll be procured and installed in the coming veạr, 
MAGNETICS AND SUPERCONDUCTIVITY SECTION ANNUAL PROGRESS REPORT

for period ending December 31, 1976

M. S. Lubell, Section Head

\begin{tabular}{|c|c|}
\hline J. E. Akinl & D. L. Levine 5 \\
\hline L. Alley & C. J. Long \\
\hline W. C. Anderson ${ }^{2}$ & J. K. Lovin \\
\hline J. K. Ballou & J. W. Lue \\
\hline R. L. Brown & J. N. Luton \\
\hline P. B. Burn ${ }^{2}$ & J. R. Miller \\
\hline W. D. Cain 2 & L. $\mathrm{Nelms}^{2}$ \\
\hline K. H. Carpenter 3 & B. E. Nelson ${ }^{2}$ \\
\hline C. V. Dodd 4 & H. Pinh $^{1}$ \\
\hline L. Dresner & J. P. Rudd \\
\hline R. B. Easter ${ }^{2}$ & H. C. Sanderson 7 \\
\hline D. S. Easton 4 & R. E. Schwall \\
\hline J. F. Ellis & J. E. Simpkins \\
\hline W. A. Fietz & S. J. Sosnowski ${ }^{2}$ \\
\hline C. M. Fitzpatrick & S. S. Shen \\
\hline K. J. Froelich & W.C.T. Stoddart ${ }^{2}$ \\
\hline W. F. Gauster 1 & P. B. Thompson ${ }^{2}$ \\
\hline J. S. Goddard 2 & L. M. Vinyard 2 \\
\hline W. H. Gray & W. H. Wagner \\
\hline C. C. Koch ${ }^{2}$ & P. L. Walstrom \\
\hline J.P. Kois ${ }^{2}$ & H. T. Yeh \\
\hline
\end{tabular}

\section{INTRODUCTION}

An annual report is being issued on a calendar year basis for the first time for two reasons. First, a report is required for the Fusion Energy Divizion Annual Progress Report, which is prepared on a calendar year basis. Second, with the change in the start of the fiscal year, it makes little sense to prepare two annual reports covering years which differ by only one quarter.

1. Consultant.

2. UCC-ND Engineering.

3. Computer Sciences Division.

4. Metals \& Ceramics Division.

5. Graduate Summer Student.

6. Fusion Energy Division.
As in the past, the quarterly report for the last quarter of the year is not issued separately since its writing and that of the annual report would coincide. However, the tabulations of visitors and staff trips cover only the last quarter.

\subsection{DESIGN PROJECTS}

\section{$1.1 .1 \quad E P R$}

The previously design Experimental Power Reactor (EPR) magnet systems (ORNL/TM-5042) were reevaluated and modified during this reporting period. Parametric studies, sensitivity checks, and detailed calculations were done for several selected subsystems. A revised design is reported in Oak Ridge Tokamak Experimental Power Reactor Study - 1976, Part 3: Magnet Systems (ORNL/TM-5574). This revised design resulted in 
a more economical and self-consistent design which is simpler in concept and easier to extrapolate to large demonstration and commercial power reactors. Some pertinent modifications are as follows.

1) The shape of the toroidal field (TF) coils was carefully reexamined. It appears that with a minor modification of the radius of curvature, the oval shape is a viable choice.

2) The fabrication of the coils was simplified by using L-shaped structural segments, each enclosing several conductor conduits. The number of weids has been greatly reduced, resulting in significant savings in both fabrication time and cost.

3) The conductor cooling paths were shortened and the protection problem eased (discharge voltage lowered) by running four conductors in parallel. The series current is then increased from 20 to 78 kA.

4) The composition of the conductor cable was optimized with respect to stability using a new theory.

5) Improved theoretical understanding of the stability of forced-flow-cooled conductors allowed us to specify quantitatively allowable sudden and gradual heat inputs for a given conductor at a specified temperature and field.

6) The required pumping power was minimized with no sacrifice in stability margin. This was achieved by flowing the helium more slowly in layers where the field is lower so as to retain the same stability mạngin.

7) Evaluations were made of ac losses in the TF coils. Because the pulsed fields have components both perpendicular and parallel to the conductor, there is an optimum choice of filament twist pitch.

8) Extensive discussion on the position of the shield vertical field (S-VF) coils has resulted in their being left inside the TF coils.
9) The poloidal field (PF) coils have been moved to decrease further the stored energy and the ampere turns required.

10) Several possible schemes for connecting the ohmic heating $(\mathrm{OH})$ coils were discussed in an attempt to find an acceptable compromise between the conflicting goals of low series current and low inductive voltage during the heating pulse.

11) Calculations of ac losses in the PF coils were made by taking into account the detailed behavior of the magnetic field inside the windings.

12) Flow paths of the helium through the $\mathrm{OH}$ coil central solennids were determined and the pumping power calculated.

13) A protection scheme for the TF coil using external dump resistors and active switching was examined in detail. Satisfactory thermal excursions, terminal voltages, and mechanical loads can be achieved by connecting the TF coils in several parallel loops and isolating and discharging only the quenching coils. The protection problems associated with the PF coils were also examined.

14) The refrigeration cycle for forced fluw includes a cold pump loop. Some experimental data on cooling of a cable by supercritical helium in forced flow are available to incorporate in updated estimates of refrigeration load.

15) Various schemes were studicd for storing and transferring the energy of the $\mathrm{OH}$ coils; however, a satisfactory scheme has not been identified, and the matter requires more extensive study.

In short, the key features of the original reference design are judged to be satisfactory. The honeycomb coil structure and forced-flowcooling by supercritical helium in a conduit remain as key features of the TF coils. It is worth noting that the modified structure can also be used with pool-boiling or convectively cooled conductors. Forced-flow-cooled conductor cable is recommended for both PF and TF coils. No 
insurmountable problems were identified in the magnet systems, including their protection, structural integrity, and long-term reliability.

Oak Ridge Tokamak Experimental Power Reactor Study - 1976.1 J. W. Lue (ed.), J. K. Ballou, R. L. Brown, R. B. Easter, C. G. Lawson, W.C.T. Stoddart, H. T. Yeh.

This part of the ORNL EPR composite report documents last year's design effort in the magnet systems. The discussion covers both the toroidal field (TF) coil system and the poloidal field (PF) coil system. Consideration of coil support structure, cryogenic requirements, and power supplies is included. Particular attention is also paid to the protection scheme of both TF and $P F$ coils. The conductor design is based on forced-flow supercritical helium-cooled cable in conduits. A hybrid system is proposed for the TF coil system; it uses $\mathrm{Nb}_{3} \mathrm{Sn}$ in the high field region for a designed maximum field of $11 \mathrm{~T}$, and $\mathrm{NbTi}$ in the low field region. Conductor stability analysis in the forced-flow scheme is discussed. Coil connection options to obtain desirable current and voltage rating in PF coils are described. The refined design of the magnet systems is more self-consistent in every respect.

Toroidal Field Coil system of the Oak Ridge EPR Reference Design. 2 J. W. Lue and J. N. Luton.

A refined design of the toroidal field (TF) coil systein for the Oak Ridge Tokamak Experimental Power Reactor (EPR) study is presented. This design is based on cable conductor cooled by forced-flow supercritical helium. It uses superconducting multifilamentary $\mathrm{Nb}_{3} \mathrm{Sn}$ for a maximum design field of 11 $T$ at the coil windings. A hybrid system which uses Nbil at low field regions is recontmended. The coil structure consists of stainless steel segments welded together to form a continuous stiff honeycomb. Conductor optimization and stability analyses specifically applicable to the forced-flow-cooled conductors are given.

\subsubsection{Demo}

A study has been made of the feasibility of using resistive coils to generate the toroidal magnetic field in a demonstration reactor. The design parameters used were: plasma major radius of $6 \mathrm{~m}$, coil ID of $5 \mathrm{~m}$, radial build of 2 $m$, and axial build of $1.4 \mathrm{~m}$. The on-axis toroidal field was $4.2 \mathrm{~T}$. The 18-member coil set, if resistive, would consume half the total electrical output of the plasma. When the power demands of other coils (such as $\mathrm{OH}$ and PF coils) and the power to drive the neutral beam injectors are considered, it becomes obvious that most of the coils will have to be superconducting. The cost of a resistive toroidal coil set was estimated to be about $350 \times 10^{6}$ dollars for about $8.75 \times 10^{6} \mathrm{~kg}\left(17.5 \times 10^{6} 1 \mathrm{bm}\right)$ of copper. It appears that some advantage could be gained from optimized geometry and reallocation of space, but a totally resistive coil set still remains unattractive on a purely economic basis.

Future studies will center on interfacing resistive and superconducting coils as well as on designing the superconducting coils.

\section{1 .3 TNS}

During the initial phase of The Next Step (TNS) TF magnet study, we supplied design criteria and machine parameters and identified feasible options for trade-off studies for the Westinghouse design team. We have reviewed and will continue to review their design and analysis studies. In these coordinated efforts, we have identified feasible designs for various TNS options which bracket physics uncertainties. Four different TF coil designs are being considered in the trade-off studies, namely: TNS-1, a watercooled copper coil with $B_{\max }=12 \mathrm{~T}$; TNS-2, a superconducting $\mathrm{NbTi}$ coil with $\mathrm{B}_{\max }=8 \mathrm{~T}$; TNS-3, a superconducting $\mathrm{Nb}_{3} \mathrm{Sn}$ coil with $\mathrm{B}_{\max }=12 \mathrm{~T}$; and TNS-4, a hybrid NbTi/copper coil with $B_{\max }$ between 8 and $12 \mathrm{~T}$. A trade-off study model, which represents subsystems in detail with a 
consistent physics and engineering rationale, has been developed.

In order to ensure a firm engineering basis in the calculation, the design of the superconducting windings has been adapted to suit the TNS operation. For example, because of the low duty cycle and high nuclear heating pulse of the TNS machine, pulsed operation of the helium fllow is proposed. The coil is to be pancake wound and the supercritical helium is to enter through the inner, high field turn and exit from the outer, low field turn. At the start of the plasma burn, the helium flow rate is increased so that the nuclear heat accumulated during the helium transit time through the first turn is kept below the superconductor stability margin. Additional stability margin is obtained when the helium reaches outer, lower field turns. As soon as the plasma burn stops, the helium filow can be reduced to just maintain stable magnet operation. By operating in this manner one can use a thin shield and still consume relatively little pumping power.

It has also been found that by operating the helium at a lower temperature and higher pumping power, a magnet designed for a given field can be extended to higher fields while maintaining the same stability margin assuming, of course, that the structure has been designed to withstand the higher mechanical load.

\section{$1.1 .4 \quad 1 \mathrm{CPP}$}

The Large Coil Program (LCP) is a separately funded project, the goals of which are to provide tested designs for. the TF coils of future generations of tokamaks and to encourage development of an industrial base for the manufacture of such coils. The LCP is supported by the technical efforts of the Superconducting Magnet Development Program (SCMDP). This effort is supplied from any group of the SCMDP as the need arises; in 1976 it was equivalent to two men full time. The SCMDP support of the LCP occurred in four main areas: technical supervision of the ERDA contracts for EPR TF coil studies; drafting of a Program Plan for LCP; preparation of a Request for Proposal for the LCP test coils; and preparation of a major Project Proposal for the LCP test facility. ERDA intended to fund three industrial contracts for conceptual studies of TF magnets for EPR, and more than three proposals were reviewed. The SCMDP helped evaluate the proposals, gave technical advice to the contractor selection committee, contributed to the orientation meeting held for potential contractors, and helped evaluate the three interim and final reports.

The SCMUP assisted in the preparation of the LCP Plan by proposing a testing configuration and size-scaling relations. The Program Plan, recommending testing at ORNL in a compact torus configuration, was approved by DMFE. scmür aiso participated in the LcP workshop in June.

To ensure wide industrial participation and a variety of candidate designs, the LCP requested proposals from industry for the conceptual design, detailed dësign, and construction of a test coil. The SCMUP assisted in preparing this Request for Proposal, particularly the section on required design and performance characteristics.

Work 15 under way to define the LCF test facility and to prepare a major Project Proposal for submission to ERDA. SCMDP personnel are participating in the effort, especially in setting the testing requirements and schedule and in matching the operation of the facility to the preexisting SCMDP helfum refrigerator.

\section{$1.1 .5 \underline{\text { EBTR }}$}

In support of the EBTR Reference Design, 3,4 two versions of the magnet system were designed. One had 48 coils with a major radius of $60 \mathrm{~m}$ (EBTR-48), and the other had 24 coils with a major radius of $24 \mathrm{~m}$ (EBTR-24). Aside from the plasma constraints, the main goal was to design coils which could be built with existing technology. The main features of the design are as follows. 


\section{Conductor design}

Monolithic NbTi superconductor was used. The average current density in the winding is $1500 \mathrm{~A} / \mathrm{cm}^{2}$; the peak field is $7.3 \mathrm{~T}$. The conductor is cryostatically stabilized by soldering the $\mathrm{NbTi-Cu}$ composite to formed copper strips with punched slots that facilitate cooling.

\section{Magnet design}

The magnets are circular, pancake wound, and cooled by liquid helium in natural convection. As long as the ratio of major radius to the number of coils is fixed, the field strength produced by modular magnets of the same size is not sensitive to the size of the reactor. Thus, an important feature and advantage of an EBTR is that modular magnets may be used in reactors of different sizes and power ratings.

\section{Protection}

To ensure adequate protection by reducing the terminal voltage during discharge, a high operating current (25 kA) is used and four conductors (each carrying 6.25 kA) are connected in parallel. To avoid problems of uneven distribution of current, a spiral winding technique has been adopted. Voltage taps are used on each coil as the main quench detection device. Pickup coils on the current leads of the power supplies are used to compensate for the inductive voltage. External dump resistors are used as heat sinks.

\section{1 .6 EBT-II}

Prel iminary designs for a toroidal array of superconducting magnets for the proposed ELMO Bumpy Torus-II (EBT-II) plasma experiment have been developed to meet the following criteria provided by the High Beta Plasma sertinn:

- maximum field on torus minor axis

- minimum field on torus minor axis

- mirror ratio

$2.0 \mathrm{~T}$

- cóil innér rádius
- x-ray heat load

$1.0 \mathrm{~W} / \mathrm{coil}$

The number of coils was to be maximized and the major radius minimized.

EBT-II has a very large aspect ratio and coil spacing compared to the TF coils of tokamaks, and the coils have only a small field asymmetry (about $2 \%$ ). Therefore, in contrast to tokamak coils, the EBT-II coils can be axisymmetric and still have a favorable (i.e., nonbending) stress distribution without requiring special support precautions. The design effort also attempted to minimize the current density and the peak field in the windings. The following results evolved:

- winding outside radius

- length $25.4 \mathrm{~cm}(10 \mathrm{in.})$

- winding cavity current density $\quad 10 \mathrm{kA} / \mathrm{cm}^{2}$

- maximum field $8 \mathrm{~T}$

- number of coils 36

- torus major radius $\quad 3.05 \mathrm{~m}(10 \mathrm{ft})$.

Several analytic studies of the behavior of these magnets have been carried out, and it appears that the magnet system can be manufactured without encountering severe development problems. Some questions still remain about which design will yield the most reliable magnet system. Therefore, we intend to build four prototype coils, each of a different design, and test them to find the most reliable. The four magnets will be of the following types:

1) potted: $\mathrm{NbTi}$ in helium at subatmospheric pressure,

2) potted: hybrid $\mathrm{NbTi}-\mathrm{Nb}_{3} \mathrm{Sn}$ in helium at atmospheric pressure,

3) unpotted NbTi,

4) unpotted hybrid $\mathrm{NbTi}-\mathrm{Nb}_{3} \mathrm{Sn}$.

The thermal studies indicate that the potted NbTi coils can operate at the estimated $x$-ray heat load; however, there is considerable doubt about the size of this heat load and about the thermal diffusivity of the coil, so the unpotted, ventilated prototypes are included. Potting was considered because of possible turn slippage due to (1) the $2 \%$ field asymmetry and (2) the possible 
addition of supplementary coils that would produce complicated stress patterns. The stress analysis systematically considered the problems of winding tension, bobbin thickness, and thermal contraction on cool-down, and it was concluded that the maximum hoop stress would be 90 $\operatorname{MPa}(13 \mathrm{ksi})$. The heat input to a coil due to superconductor hysteresis effects if its neighbor were to quench was calculated to be $11.7 \mathrm{~J}$ total, with a peak value of $980 \mathrm{~mJ} / \mathrm{cm}^{3}$. The maximum temperature reached in a quench was calculated to be $75 \mathrm{~K}$, a safe value.

\subsection{SMALL SCALE EXPERIMENTS}

\subsubsection{Pulsed Parallel Field}

A series of experiments was carried out to examine losses in twisted multifilamentary composite superconductor when it is exposed to transient magnetic fields applied parallel to the longitudinal direction of the conductor. The usual practice of twisting the filaments of a composite conductor about its axis to decouple them from transient transverse magnetic fields enhances coupling (and thus the losses) in the presence of time-varying parallel fields. The TF coils of tokamak devices will be exposed to both transverse and parallel components of pulsed magnetic field over parts of their windings.

The most recent experimental results were reported by Miller and Shen at the 1976 Applied Superconductivity Conference in Palo Alto. This work demonstrated the difficulty of saturating the filaments of larger conductors when they carry no current and the ease of saturating the same conductors when they carry current near the critical value. Of course the latter case is the important one because any TF coil will be designed to operate at some large fraction of the critical current.

Because the interest of our program lies naturally with larger conductors, apparatus capable of examining larger conductors has been designed and is under construction. As in previous apparatus, the test conductor will be exposed to pulsed parallel fields by placing it instde a torus. Previously, however, the test conductor was wound into a thin solenoid and the torus was wound around it. In the apparatus being constructed, the torus is wound around a spool which can be rotated via a chain and sprocket to pull the test conductor in from the outside; thus, the torus need not be destroyed every time the sample is changed.

The torus windings of the new apparatus will be superconducting to allow a ramp and hold of the parallel fleld. The Illaximum Narallel field component should be about $1.5 \mathrm{~T}$ and the maximum ramp rate should be about $3 \mathrm{~T} / \mathrm{sec}$ if we use an available 30-V, 500-A motor-generator set to charge the torus. Controls for the set have already been designed and are ready for construction. The torus will initially be operated in a dewar inserted in a water-cooled copper solenoid that will provide a 6-T transverse field at the test conductor. Current to the test conductor will be provided through 5000-A, vaporcooled leads.

\subsubsection{Propagation and Stability Tests}

Conductors cooled by boiling helium

Last yoar, calculations of propagation velocities that took into account current sharing and the temperature variation of the material properties of matrix and superconductor were carried out. These calculations were based on the restrictive assumption of a constant heat transfer coefficient. This year, this restric. tion was dropped, and full account is now taken of the temperature variation of the heat transfer at a copper-helium surface in the nucleateboiling, transition, and film-boiling ranges. A new numerical method was developed to carry out the calculations. Comparison of the calculations with earlier measurements of Miller and Donaldson 5 indicates the need to include the effects of transient heat transfer in the calculations in order to achieve agreement between theory and experiment. An account of this work has been published in Cryogenics. 
Measurements were undertaken to determine the stability of various composite conductors in realistic coil environments. The velocity of propagation or contraction of normal zones, the full recovery current, and the minimum propagating current were measured. The dependence of these quantities on background field, transport current, electrical insulation, cooling passage size and orientation, and proximity of other conductors was examined. The measured velocities of propagation were compared with those calculated with the theory mentioned above, and good agreement was achieved once an allowance was made for transient heat transfer. This work was described in a paper given at the 1976 Applied Superconductivity Conference.

Propagation of Normal Zones in Composite Superconductors. ${ }^{6} \mathrm{~L}$. Dresner. This paper describes calculations of propagation velocities of normal zones in composite superconductors. Full account is taken of (1) current sharing, (2) the variation with temperature of the thermal conductivity of the copper matrix and the specific heats of the matrix and the superconductor, and (3) the variation with temperature of the steady-state heat transfer at a copper-helium interface in the nucleate-boiling, transition, and film-boiling ranges. The theory, which contains no adjustable parameters, is compared with experiments on bare (uninsulated) conductors. Agreement is not good. It is concluded that the effects of transient heat transfer may need to be included in the theory to improve agreement with experiment.

\section{Investigation of Stability of Composite} Superconductors in Typical Coil Configurations. 7 J. R. Miller, J. W. Lue, and L. Dresner. The stability of various composite conductor designs in realistic coil environments has been examined. We measure the velocity of propagation or contraction of a normal region, the full recovery current, and the minimum propagating current in a coil segment. We examine the dependence of these measurements on background field, transport current, electrical insulation, cooling passage size and orientation, and proximity of other conductors.
Comparison of experiment and calculation provides indirect information about local heat transfer to the helium bath and direct information about safe operating current limits for particular coil designs.

\section{Forced-cooled conductors}

A computer program was written last year to calculate the temperature-time history of a uniformly pulse-heated $\mathrm{NbTi-Cu}$ conductor cooled by supercritical helium in forced convection. Using this program, one could find by trial and error the maximum sudden heat addition $(\Delta H)$ that still allowed recovery of the superconducting state. This year the progam was improved by eliminating the trial and error feature, which resulted in an order of magnitude increase in the speed of the program. The faster running of the program allowed $\Delta H$ to be maximized by factorial search with respect to simultaneous variation of the helium volume fraction and the copper-to-superconductor ratio. Conductors with $\Delta H$ so maximized are called stability-optimized conductors; the use of these conductors in magnet design minimizes pumping power and pressure drop for a preassigned stability level $\Delta H$. The design method based on these considerations was described in a paper given at the 1976 Applied Superconductivity Conference. Practical use of the method has already been made in aiding selection of forced-cooled conductors for purchase by the Magnetics and Superconductivity Section.

Stability-Optimized, Forced-Cooled, Multifilamentary Superconductors. ${ }^{8} \mathrm{~L}$. Dresner. A numerical program has been written to calculate the temperature-time history of a uniformiy pulse-heated composite superconductor cooled by supercritical helium in forced convection. The program determines the maximum sudden temperature rise from which the conductor can still recover the superconducting state. The program includes the effects of (1) current sharing, (2) the temperature variation of the specific heat of both the matrix and the superconductor, and (3) the temperature variation of the heat transfer coefficient. Using this program, one may optimize 
forced-cooled conductors with respect to stability by simultaneously varying the copper-tosuperconductor ratio and the metal-to-helium ratio. Use of stability-optimized conductors allows a given stability level to be maintained for a particular field and bath temperature and the pressure drop and pumping losses to be reduced.

\subsubsection{Conductor Design and Tests}

\section{Conductor designs}

NbTi conductor. Early this year a study of TF conductors was undertaken. A set of basic criteria covering operating current, ac losses, stability, mechanical properties, and insulation requirements was established. Several conductor designs were proposed, and four of these - three pool-boiling and one forced-flow - were analyzed in detail and were shown to meet the projected needs of tokamak machines.

This study showed that the conductor geometry is strongly affected by ac loss requirements. They can be most easily met by using some form of cabling technique. The question of how this form of conductor construction affects stability was investigated by Fietz and Dresner, who examined current transfer between strands in a cable which were coupled either inductively or by a resistive matrix. Dresner studied the effect of the resistive matrix on stability in cables, some of the strands of which were composite superconductors and the remainder of which were pure copper.

As a result of these studies a specification (ORNL-7D-SP\#192) detailing the performance expected of TF conductors was prepared. This specification formed the basis of a request for quotation (RFQ) that was submitted for competitive bidding. The RFQ did not specify conductor design, but asked the manufacturer to propose his own design, analyze it, and bid on a fixed price basis. In order to stimulate interest and innovative design, it was stated that ORNL might purchase other conductors in addition to the low bid if they were of sufficient interest. To guide the manufacturers, Fietz presented some conductor designs and analyses at the 1976 Applied Superconductivity Conference.

After receipt of conductor proposals in response to the RFQ, two pool-boiling conductors were ordered. Six hundred meters of each conductor (rated at 10,000 A in a perpendicular magnetic field of $8 \mathrm{~T}$ ) were requested. Negotiations were also initiated for further development work on two forced-flow conductors and one additional pool-boiling conductor.

$\mathrm{Nb}_{3} \mathrm{Sn}$ conductor. A mechanical testing program was carried out with the Metals and Ceramics (M\&C) Division to characterize available multifilamentary $\mathrm{Nb}_{3} \mathrm{Sn}$. This program is described under the mechanical testing section.

Material which had previousiy been purchased in the form of a 7-strand cable was heat treated to optimize its performance, and a forced-flow $\mathrm{Nh}_{3}$.Sn rondurtonr was dessigned on the basis of this cable. Initial experimental work necessary for its fabrication was performed.

A length of fine, unreacted multifilamentary $\mathrm{Nb}_{3} \mathrm{Sn}$ wire was purchased for evaluation in pulsed coil operation. The preliminary design was completed for its use in a pool-boiling hybrid coil with NbTi cable in the low field regions and $\mathrm{Nb}_{3} \mathrm{Sn}$ cable in the high field regions.

Discussions were begun with vendors for develnpmental wnrk in the manufarture of $\mathrm{Nb}_{3} \mathrm{Sn}$ forced-flow conductors for TF coils.

High Current Superconductors for Tokamak Toroidal Field Coils. ${ }^{9}$ W. A. Fietz, Conductors rated at $10,000 \mathrm{~A}$ for $8 \mathrm{~T}$ and $4.2 \mathrm{~K}$ are being purchased for the first Large Coil Segment tests at ORNL. Requirements for these conductors, in addition to the high current rating, are low pulse losses, cryostatic stability, and acceptable mechanical properties. The conductors are required to have losses less than $0.4 \mathrm{~W} / \mathrm{m}$ under pulsed fields of $0.5 \mathrm{~T}$ with a rise time of $1 \mathrm{sec}$ in an ambient 8-T field. Methods of calculating these losses and techniques for verifying the performance by direct measurement are discussed. Conductors stabilized by two different cooling methods, pool-boiling and forced helium flow, have been proposed. Analyses of these conductors 
are presented, and proposed definitions and tests of stability are discussed. Mechanical property requirements (tensile and compressive) are defined, and test methods are discussed.

\section{Mechanical tests}

The studies of multifilament superconductors under mechanical load which were begun last year have continued through most of 1976. NbTi superconductors with both copper and aluminum matrixes have been studied, as well as a number of $\mathrm{Nb}_{3} \mathrm{Sn}$ cables and monolithic conductors. The results of this work have been reported in the literature.

Evidence has also been found for thermomechanical heat generation in NbTi composites. Preliminary results and calculations indicate that this heating may be comparable in magnitude to that due to magnetic hysteresis for a poloidal coil system.

The following are abstracts of papers published during the past year. (Other presentations were also given. $10-13$ )

Performance of Multifilamentary $\mathrm{Nb}_{3} \mathrm{Sn}$

Under Mechanical Load. ${ }^{14}$ D. S. Easton and R. E.

Schwal1. The critical current of a commercial multifilamentary $\mathrm{Nb}_{3} \mathrm{Sn}$ conductor has been measured under the application of uniaxial tension at $4.2 \mathrm{~K}$ and following bending at room temperature. Significant reductions in $J_{C}$ are observed under uniaxial loading. Results are presented for a monolithic conductor manufactured by the bronze-diffusion technique and for cable conductors formed by the tin-dip technique.

Thermomechanical Heat Generation in Copper and a Nb-Ti Superconducting Composite. 15 ก. S. Faston, D. M. Kroeger, and A. Moazed. Heat generation via tensile stresses in both purc copper and a superconducting Nb-Ti composite was studied at 300 and $4.2 \mathrm{~K}$. L.inear thermoelastic behavior was found at room temperature but not at $4.2 \mathrm{~K}$. At $4.2 \mathrm{~K}$, stress levels on the order of $88 \mathrm{MPa}$ and $0.1 \%$ strain produced energy losses of $1-2 \times 10^{5} \mathrm{~J} / \mathrm{m}^{3}$. When stress-cycled under adiabatic conditions, the composite showed a temperature increase with each cycle as a result of nonlinear (hysteretic) stress-strain behavior.

Stress-Induced Heating in Commercial Conductors and Its Possible Influence. on Magnet Performance. ${ }^{16}$ D. M. Kroeger, D. S. Easton, and $A$. Moazed. Calorimetric measurements show that significant amounts of heat are generated when a multifilamentary composite conductor is stressed in tension to levels expected to occur in large, high field magnet systems. When the stress on the conductor is repetitively cycled between zero and some maximum value, the amount of heat produced per cycle is constant after the first few cycles. Comparison is made between calorimetric determinations of heat injections and the work done on the specimen as indicated by stress-strain curves. Stress-strain curves for a number of commercial conductors indicate that the most important determinant of the magnitude of this effect is the choice of matrix material.

Measurement facilities

A short sample test facility comprising a 2000-A sample holder and a 7.9-T, 10-cm-bore, $\mathrm{NbTi}$ solenoid was put into operation for routine conductor testing. An additional 5000-A sample holder was constructed for testing conductor in the $8-T, 16-\mathrm{cm}$-bore, water-cooled copper solenoid. Conductor was purchased and tested and prel iminary design completed for a 15-cm-bore, 5-cm-gap, split solenoid. The coil is designed to produce a central field of $7.8 \mathrm{~T}$ with the help of iron pole pieces. The maximum field in the windings will be $7.0 \mathrm{~T}$. Clear access of $1-7 / 8$ in. diam will be sufficient for testing of all conductors of LCS size.

\subsubsection{Pulse (Poloidal) Coils}

Poloidal field coil development by the SCMDP has been initially directed toward those aspects of the PF system which are deviceindependent, i.e., those areas in which work can be pursued independent of the detailed design of TNS. Given the limited resources available 
within the SCMDP for PF coil work, we feel that this approach has provided and will cortinue to provide the most usable information from the effort being expended.

\section{Loss measurements}

A pulse loss measurement system was completed. The system consists of fiberglass dewars, ramp power supply, Rogowski coils, and a PDP-12 computer. Test data are recorded and analyzed digitally. The method yields not only the total energy loss but also the loss voltage waveform. Measurements have been performed on three difterent. pulse coil syst.ems. 17

Discharging magnets may be a useful way of operating the poloidal coils in a tokamak fusion reactor. A discharge test has been performed on one pulse coil. The results have shown that the magnet can be discharged from 6.2 \% at a rate of $10 \mathrm{~T} / \mathrm{sec}$ without going normal. Filamentary hysteresis losses, coupling losses, eddy current losses in normal metal, and losses due to conductor motion have been individually identified and measured.

Pulse Loss and Voltage Measurements on Superconducting Magnets. 18 S. S. Shen and H. T. Yeh. This paper describes an electrical method for measuring pulse losses and compensated voltage in superconducting magnets. Test results from two pulsed solenoids were recorded and analyzed digitally by computer. Dependence of loss performance on $B_{\max }$ and $\dot{B}$ is studied. The effects of conductor motion and presence of normal metal on the loss performance are also discussed.

Experimental Simulation of Pulsed Field Losses in Tokamak Toroidal Field Coils. ${ }^{19}$

J. R. Millor and S. S. Shen. Experiments have been carried out to measure loss in a twisted multifilamentary composite superconductor when exposed to a transient longitudinal field. We investigated the variation of losses both as a function of transverse applied field and of sample transport current. Losses are probed mainly by measurement of the dynamic resistivity of the sample during the longitudinal pulse. Experimental results are compared with theories for the zero transport current case. The extension of theory to include transport current is also discussed, and the impact on tokamak toroidal field coil design is considered.

\section{Quench detection}

A fault detection and protection scheme has been suggested, based on measurements of instantaneous loss voltages. Such a scheme has also been designed for the toroidal. coil system of the EPR. 20

\section{Loss calculations in coils}

A compliter code named PLASS has been developed to calculate composite conductor losses in pulsed poloidal systems of tokamak machines.

A Computer Program to Calculate Composite Conductor Losses in Pulsed Poloidal Coil Systems. ${ }^{21}$ W. H. Gray and J. K. Ballou. In the design of the cryogenic system and superconducting magnets for a poloidal field system in a tokamak fusion reactor, it is important to have an accurate estimate of the heat produced in the superconducting magnets as a result of the rapidly changing magnetic fields. Until recently, this estimate was obtained by assuming that the field and the time rate of change of the field were constant throughout the coil windings. A more accurate method of estimation involves integrating the losses over the coil windings, thus taking into account the spatial variation of the magnetic field. A eomputer code, rLASS (Pulsed Losses in Axisymmetric Superconducting Solenoids), has been written to perform this integration.

PLASS has been used to analyze the present design for the poloidal coil system of the ORNL Experimental Power Reactor (EPR). This design requires that superconductor hysteresis losses, superconductor coupling losses, stabilizing material eddy current losses, and structural material eddy current losses be taken into consideration in the calculation of conductor losses. A tabulation of individual losses vs variations in superconductor characteristics and coil current changes is presented to demonstrate 
the parameters which significantly affect the design. Results indicate that the total energy release into the cryogenic system is less than one-half of that predicted by the previously oversimplified calculation.

An Estimate of Thermoelastic Heat Production from Superconducting Composites in Pulsed Poloidal Coil Systems. ${ }^{22}$ J. K. Ballou and W. H. Gray. In the design of the cryogenic system and superconducting magnets for the poloidal field system in a tokamak, it is important to have an accurate estimate of the heat produced in superconducting magnets as a result of rapidly changing magnetic fields. A computer code, PLASS (Pulsed Losses in Axisymmetric Superconducting Solenoids), was written to estimate the contributions to the heat production from superconductor hysteres is losses, superconductor coupling losses, stabilizing material eddy current losses, and structural material eddy current losses. Recently, it has been shown that thermoelastic dissipation in superconducting composites can contribute as much to heat production as the other loss mechanisms mentioned above. We discuss a modification of PLASS which takes into consideration thermoelastic dissipation in superconducting composites. A comparison between superconductor thermoelastic dissipation and the other superconductor loss mechanisms is presented in terms of the poloidal coil system of the ORNL Experimental Power Reactor Design.

\section{Pulse coils}

Two new coils were constructed to achieve maximum rate of rise in a design that would be scalable to large sizes.

ORPUS-1. ORPUS-1 (Oak Ridge Pulsed Solenoid), a reinforced, highly ventilated solenoid wound from copper-matrix, formvarinsulated, NbTi compacted cable, has been constructed and tested. The coil attained the design field of $4 T$ and can be charged at 2 rate of $2 \mathrm{~T} / \mathrm{sec}$ (limited by the power supply on iy).

ORPUS-2. ORPUS-2, with the same structure as that of ORPIIS-1, has been wound from solderfilled NbTi compacted cable. A number of heaters and voltage taps are embedded in the windings so that normal zone propagation can be studied and the recovery current determined. ORPUS-1 - A Pulsed Superconducting

Solenoid. ${ }^{23}$ R. E. Schwall. The tokamak fusion reactors presently proposed require very large, pulsed, superconducting magnets for plasma breakdown and ohmic heating. These magnets are unique in their simultaneous requirements of high maximum field $(B \approx 7 \mathrm{~T}$ ), high charging rate $(B \approx 7 \mathrm{~T} / \mathrm{sec})$, and bipolar operation. This paper describes the first of a series of magnets designed to develop the needed pulsed magnet technology. ORPUS-1 is an 8-cm-bore, $25-\mathrm{cm}-$ long solenoid wound of 11 -strand, copper-matrix NbTi cable. The coil is designed to operate at $4.2 \mathrm{~T}$ at $2000 \mathrm{~A}$ and to be charged at $4 \mathrm{~T} / \mathrm{sec}$. With the exception of cowound stainless steel reinforcement, the structure is entirely nonmetallic. The coil is not potted and more than $50 \%$ of the conductor surface is exposed to helium. Data on dc and pulsed performance and on heat generation during pulsed operation are presented.

\subsubsection{Instrumentation}

Instrumentation work has been directed mostly toward mechanical and electrical measurements and data acquisition. Accomplishments include the development and evaluation of needed transducers that are not commercially available and the design of systems around data handling devices that are commercially available.

\section{Mechanical measurements}

Linear displacement transducers. Five moving coil differential transformers (MCDT) were fabricated and calibrated. Three of these units were installed and operated satisfactorily in the three-coil cluster test of the Princeton Large Torus TF coils at Princeton Plasma Physics Laboratory. As previously reported (period ending June 1, 1976) the MCDT exhibited a $1 \%$ increase in output when it was axially aligned. parallel to a $6-r$ magnetic field and excited at 
$10 \mathrm{kHz}$ by a commercial carrier amplifier-demodulator having a $4-\Omega$ carrier output. This was due to vibrations of the transducer's windings caused by Lorentz forces. More recent experiments revealed that because of effective changes in the reactance of the primary winding, this error became larger and somewhat unpredictable when the transducer was excited by a $600-\Omega$ source. The phase-angle dependence of this error signal was then determined, and a method was devised for reducing it to within $\pm 0.3 \%$ for any field up to $7.5 \mathrm{~T}$ at either ambient temperature or $4.2 \mathrm{~K}$. A method was devised for correcting the transducer's temperature coefficient to within $1 \%$ for operation at either ambient temperature or $4.2 \mathrm{~K}$.

Eddy current displacement transducer. An eddy current displacement transducer (ECDT) was developed to serve as a miniaturized comparison to the MCDT. Its intended uses are to measure small linear displacements in coils and to serve as a sensing device for bellows deflection in liquid helium pressure transducers. It differs from the MCUr in that the sensitive element is a copper (or other highly conductive nonmagnetic metal) slug, movable within two opposing coils operating at $2.7 \mathrm{MHz}$. The physical size of the first prototype is $0.95-\mathrm{cm}$ diam by $5.1-\mathrm{cm}$ length, the gaging range is 7.5 $\mathrm{mm}( \pm 3.75 \mathrm{~mm})$, linearity is $\pm 2.5 \%$, and sensitiv$i$ ty is $400 \mathrm{mV} / \mathrm{mm}$. The device has not yet been tested in intense magnetic fields under liquid helium.

Expendable eddy current proximity transducer. An expendable eddy current proximity transducer has been developed for noncontacting measurements of small mechanical displacements in very high magnetic fields at ambient as well as cryogenic temperatures. It is intended for use in conductor motion studies and as a sensing element for diaphragm deflection in liquid helium pressure transducers. It is basically a modification of an earlier ORNL development (U.S. Patent No. 3609-527) and differs from most of the commercial proximity transducers by containing no ferromagnetic material. It operates with the same electronic module used for the ECDT. The sensitivity (dc output) of the prototype was $150 \mathrm{mV} / \mathrm{mm}$ over a gaging range of $6.4 \mathrm{~mm}$ with a linearity of $\pm 1.3 \%$. It is suitable for use with any high conductivity metal surface such as copper or aluminum. It has not been tested in high magnetic fields under liquid helium.

Strain gages and cements. Platinumtungsten gages were investigated for use in magnet testing and were found to have a considerably lower $\mathrm{dR} / \mathrm{dT}$ at $4.2 \mathrm{~K}$ than Karma alloy gages. These gages need to be tested for low magnetoresistance and mechanical liysteres/s befure they are fully yualified for magnet use, however. Two strain gage cements, AE10 and AE15, ubtained fruin MlcruMeasurements Corporation, were found to be satisfactory for cryogenic use. They have the advantage of not requiring a high temperature cure, which is not feasible with large test pieces (e.g., large magnets).

Liquid hel ium pressure and flow. A product search for pressure and flow transducers suitable for use with liquid helium was conducted. While a few commercial devices appeared promising, none was found which clearly met all the requirements. Therefore, the development of a differential pressure transducer for use in intense magnetic fields was begun.

\section{Electrical measurements}

Coil eurrent. A Rogowsiki coil with a novel coaxial bus arranyemenl for medsuring dI/dT in a magnet soil was developed. The current flows through the center and back around the outside of the Rogowski coil in the coaxial bus to cancel the external fiold which would otherwiso be induced. The entire device is enclosed in a heavy magnetic shield, the effectiveness of which is maximized by the cancellation of the induced external field. A prototype embodying the concept was fabricated and is in use in the pulsed coil program, where the amplified output of the Rogowski coil is subtracted from the magnet coil terminal voltage in order to yield the in-phase signal. The concept is also intended for use in 
toroidal coil tests where a similar subtraction will be made in order to detect the IR drop in normal zones.

Coil voltage. A voltage tap signal conditioning unit, quench detection circuit, and dump control unit were designed and fabricated. The voltage tap unit consists of a ten-channel, high-voltage isolation amplifier system with analog subtraction of $\mathrm{dI} / \mathrm{dT}$ signals from Rogowski coils. The quench detection circuit produces a TTL logic sigral when an IR signal either instantaneously exceeds a preset high level or exceeds a preset lower level for a preset time. The dump control circuit takes the output of the quench detection circuit and the output of the comparators or other quench indicators (e.g., pressure transducers), and initiates a dump when given a TTL signal.

\section{Data acquisition}

A revised automatic data acquisition system was designed after an earlier proposed system was delayed by lack of capital funding. The revised system is designed to allow expansion to handle the LCP by addition of parallel processors with buffer memory. The parallel processors are microcomputers (LSI-11 or equivalent). An A/D unit on each of the outboard processors accesses the memory directly in order to achieve the necessary throughput. $\frac{\text { A Moving-Coil Linear Variable Differential }}{\text { Transformer. }}$ Walstrom.

A moving coil linear variable differential transformer with no ferromagnetic components has been developed. The device retains all the advantages of the conventional moving coil linear variable differential transformer (high sensitivity and high output signal, infinite resolution, excellent linearity, and wide dynamic range) but is virtually unaffected by ambient magnetic fields up to $7.5 \mathrm{~T}$. The sensitivity of the device was measured to be $18 \mathrm{mV} / \mathrm{mm} / \mathrm{V}$. Linearity was determined to be $\pm 0.1 \%$ and $1 \%$ over $1-\mathrm{cm}$ and $2-\mathrm{cm}$ gaging ranges, respectively, when the transducer was excited by a commercial carrier amplifier unit at an excitation level of $5 \mathrm{~V}$ rms at $10 \mathrm{kHz}$.
Controlled Thermonuclear Fusion Reactors. ${ }^{25}$ P. L. Walstrom.

Controlled production of energy by fusion of light nuclei has been the goal of a large portion of the physics community since the 1950 's. In order for a fusion reaction to take place, the fuel must be heated to a temperature of 100 million ${ }^{\circ} \mathrm{C}$. At this temperature, matter can exist only in the form of an almost fully ionized plasma. In order for the reaction to produce net power, the product of the density and energy confinement time must exceed a minimum value of $10^{20} \mathrm{sec} \mathrm{m}^{-3}$, the so-called Lawson criterion. Basically, two approaches are being taken to meet this criterion: inertial confinement and magnetic confinement. Inertial confinement is the basis of the laser fusion approach; a fuel pellet, imploded by intense laser beams from all sides, ignites. Magnetic confinement devices, which exist in a variety of geometries, rely upon electromagnetic forces on the charged particles of the plasma to keep the hot plasma from expanding. Of these devices, the most encouraging results have been achieved with a class of devices known as tokamaks. Recent successes with these devices have given plasma physicists confidence that scientific feasibility will be demonstrated in the next generation of tokamaks; however, an even larger effort will be required to make fusion power commericially feasible. As a result, emphasis in the controlled thermonuclear research program is beginning to shift from plasma physics to a new branch of nuclear engineering which can be called fusion engineering, in which instrumentation and control engineers will play a major role. Among the new problem areas they will deal with are plasma diagnostics and superconducting coil instrumentation.

Cryogenic Instrumentation Needs in the Controlled Thermonuclear Research Program. ${ }^{26}$ P. L. Walstrom.

The magnet development effort for the controlled thermonuclear research program will require extensive testing of superconducting coils at various sizes from small-scale models to 
full-size prototypes. Extensive use of diagnostic instrumentation will be necessary to make detailed comparisons of predicted and actual performance in magnet tests and to monitor the test facility for incipient failure modes. At later stages of the program, cryogenic instrumentation will be needed to monitor magnet system performance in fusion power reactors. Measured quantities may include temperature, strain, defiection, coil resistance, heliun coolant pressure and flow, current, voltages, etc. The test environment, which includes high magnetic fields (up to 8-10 T) and low temperature, makes many commercial measuring devices inoperative or at least inaccurate. In order to ensure reliable measurements, careful screening of commercial measuring devices for performance in the test environment will be required. A survey of potentially applicable instrumentation is presented, along with available information on operation in the test environment, based on experimental data or on analysis of the physical characteristics of the device. Areas where further development work is needed are delineated.

\subsection{LARGE COIL EXPERIMENTS}

\subsubsection{Large loul Segment lest}

The Large Coil Segment test was conceived in 1976 as a test stand for the LCP-TNS generation of high current (10-20 kA) composite conductors and for winding designs using these conductors. It will provide essential data on the limits of cryostability of these conductors on a physically meaningful scale and thus will provide information which cannot bo obtained by short sample or small magnet tests.

The facility is designed to accommodate test coils up to $\sim 3 \mathrm{~m}$ in diameter of either modifiedD, oval, or circular shape, with a winding cross section of up to $12 \times 20 \mathrm{~cm}$ with up to 260 turns. The test coil winding will be subjected to a total field of 27 T over a $0.6-\mathrm{m}$ length, the background field being provided by a set of superconducting $\mathrm{Nb}_{3} \mathrm{Sn}$ tape coils obtained from the old IMP plasma physics facility and rearranged in a new configuration. The coils were successfully tested in their old configuration to $95 \%$ of short sample critical current with no damage. A bell-jar vacuum will be provided by a vacuum tank salvaged from the ORMAK facility and modified by addition of a 1.22-m-diam cylindrical extension at the top hatch of the lid. The tank, along with test coil, background coils, and support structure, is shown in Fig. 5.1.

On October 1, 1976, a conceptual design and proposal were completed by Design Engineering and SCMDP personnel. The proposal was not submitted as a separate formal proposal because at that tîme it wàs decided tö incilude thè LCS facility in the overall LCP facility. The conceptual design included fieid and force calcuilations, mechanical structure design, cryogenic design, electrical system design, vacuum system design, a facility instrumentation design, and an overall layout.

On the basis of conductors which were ordered (see Sect. 5.2.3) or under consideration, winding schemes for five test coils were laid out. Detail design of the coils and bobbins was inftiated.

\section{$1: 4$ PROJLCTS BASED ON DISCITLINES}

\subsubsection{PrulecLliun Allalys Is and Edaly Currenll Calculations}

Protection analysis

Quench detection. 27 An electrical method for measurement of ac loss voltages has been developed to compensate for the large inductive voltages caused by charging and discharging of magnets. A pirkup rnil is placed at the current leads of each power supply. Loss voltages as small as $0.1 \%$ of the inductive voltage have been detected.

Coil interaction and protection. We have studied the mutual interaction between toroidal and poloidal coils during normal and fault conditions and the effect of plasma discharge on the first wall as a result of coil quenches. Temperature rise, induced voltage, and mechanical load on coils due to their mutual interaction 


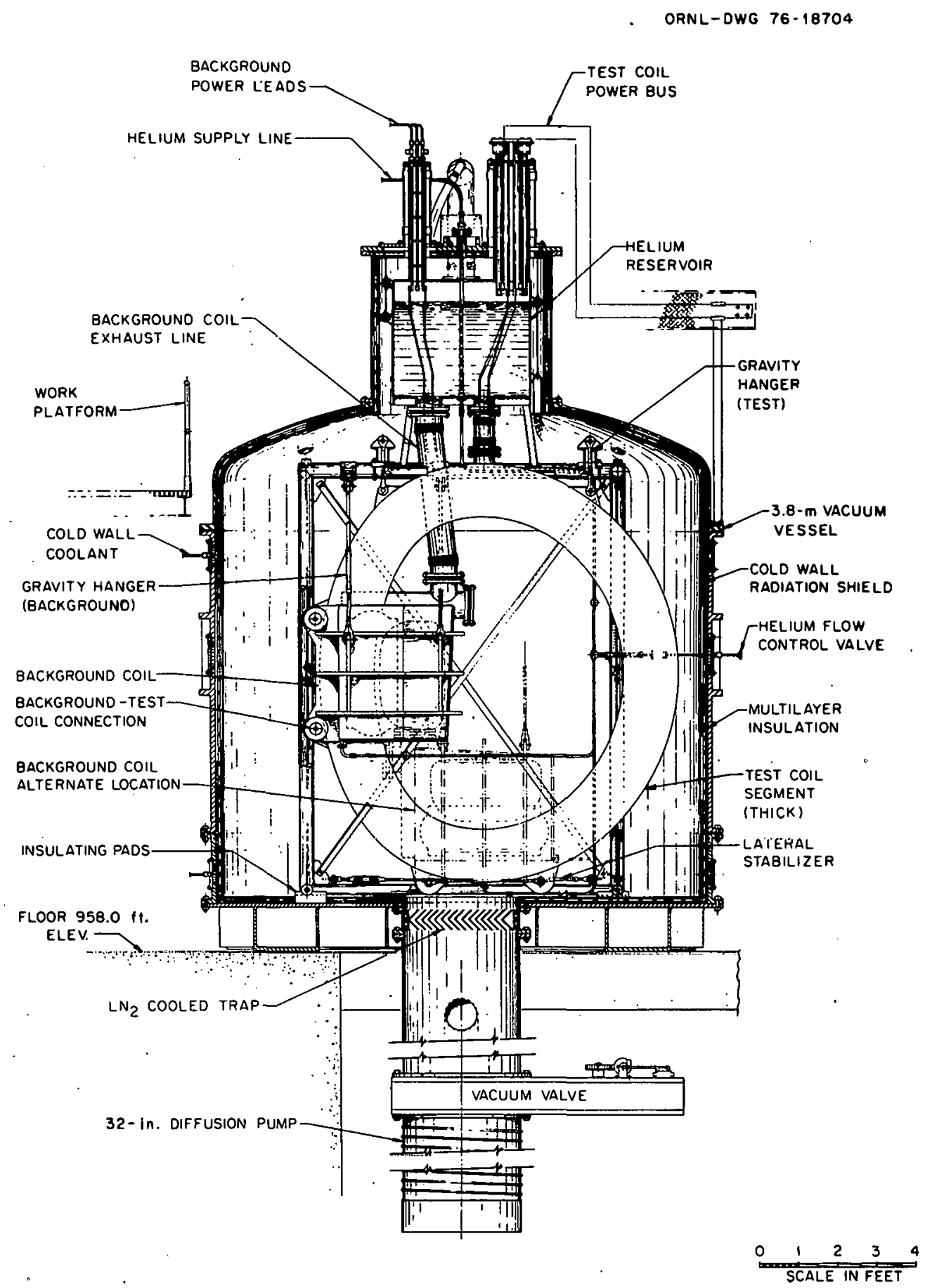

Fig. 1.1. Large Coil Segment test facility. 
have been computed. For the Oak Ridge EPR design, connecting symmetrically located Tf coils in groups and isolating and discharging only the faulty coils result in satisfactory discharge voltages and temperature rises in the coil.

The Interaction and Protection of Superconducting Poloidal Field Coils and Toroidal Field Coils in a Tokamak Experimental Power Reactor. 28 H. T. Yeh and J. W. Lue. The protection problems of superconducting coils in a large tokamak device are delineated. Effects of the plasma discharge on the first wall, the induced voltage, and the temperature rise during the quench of a superconducting coil, as well as the mechanical load on coils due to their mutual interaction under normal or fault conditions, are discussed. Various design choices and protection schemes are used to ensure the integrity of the coils during quench. For the Oak Ridge EPR design, a scheme of connecting symmetrically located toroidal field coils in groups and isolating and discharging the faulty coil only gives satisfactory results.

\section{Eddy current calculations}

A 2-D computer code has been developed to solve axially symmetrical eddy current problems, including those in which iron is present. Rapid relaxation is achieved by combining coarse and fine lattices in the transition region between air and iron. The program can be run interactively on a time sharing computer.

Eddy current codes have also been developed for thin, nonmagnetic rectangular plates and cylinders of finite length. The transient eddy current was found by solving the integrodifferential equation in the form of a perturbation expansion with separated time dependence. No reference to field values outside the conductor is required. The time variation of the driving field is fitted by a polynomial in time. The effects of the boundary charges in modifying the eddy current pattern are taken into account.
A Two-Dimensional Relaxation Program for Systems with Inhomogeneous Permeability. ${ }^{29}$

W. E. Deeds and C. V. Dodd. A computer program is presented and explained which will solve axially symmetric eddy current problems, including those with permeable media present. An unusual feature is the combination of coarse and fine lattices, which permits rapid relaxation of coarse lattices in homogeneous regions to be combined with more accurate calculations using a fine lattice in the transition regions where the permeability varies. Although the actual program listed is restricted to coils encircling a coaxial metal rod, the program can be modified to include any axially symmetric configuration.

\section{A Perturbation Expansion with Separated} Time Dependence for Eddy Current Calculations. ${ }^{30}$ K. H. Carpenter and H. T. Yeh. A particular solution to the eddy current integro-differential equation is found in the form of a perturbation expansion with separated time dependence. No reference to field values outside the conductor is required and a full three-dimensional treatment is maintained. Transient behavior of the eddy currents is obtained by this method through a technique of fitting the time variation of the driving field with a polynomial in time. As an example, the case of a thin plate of constant conductivity is studied. The eddy current distribution is obtained as a function of time for the external magnetic field of a dipole having ramp time dependence and with the dipole axis perpendicular to the plate. The effects of the boundary charges in modifying the eddy current pattern are illustrated.

Eddy Current Calculations for Thin Cylinders of Finite Length with Driving Fields of Ramp Time Dependence. ${ }^{31}$ K. H. Carpenter and H. T. Yeh. Eddy current density for a thin cylinder of finite length is calculated for the case of a driving field of ramp time dependence and dipole spatial dependence, the dipole being at the center of the cylinder. The calculations are made by using a perturbation expansion of the eddy 
current integral equations with a polynomial approximation to the time factor of the driving term. The steady-state solution, presented as an arrow plot, shows the effects of edge charges forcing currents to remain within the conductor. The transient solutions show that the entire geometrical pattern of the steadystate eddy currents is approached uniformly in the typical exponential manner of diffusion equations. Typical transient curves are given. All calculations are in normalized coordinates to allow maximum flexibility in applications. FORTRAN Programs for Transient Eddy Current Calculations Using a PerturbationPolynomial Expansion Technique. ${ }^{32}$ K. $\mathrm{H}$. Carpenter. A description is given of FORTRAN programs for transient eddy current calculations in thin, nonmagnetic conductors using a perturbation-polynomial expansion technique. Basic equations are presented as well as flow charts for the programs implementing them. The implementation is in two steps - a batch program to produce an intermediate data file and interactive programs to produce graphical output. FORTRAN source listings are included for all program elements, and sample inputs and outputs are given for the major programs.

\subsubsection{Structural Amalysis and Material Tests}

\section{Structural analysis}

The structural analysis portion of the program concerns itself with analysis of magnetic fields, electromagnetic forces, and structura] response of electromagnetic devices. Major.accomplishments were achieved in five areas:

1) the development and refinement of an analytical solution for the mechanical response of a transversely isotropic solenoid;

2) the implementation of computer code GFUN-30;

3) the completion of a photoelastic analysis of TF coils;
4) the numerical approximation of superconducting losses in solenoids of the ORNL EPR poloidal coil system by using the finite element method; and

5) the implementation of the GIFTS-IV computer code.

The details of these projects are discussed individually in the following sections.

W. H. Gray attended the GIFTS-IV workshop at the University of Arizona during the week of June 9, 1976. Subsequently, the GIFTS-IV computer program was implemented on the FED PDP-10. The GIFTS-IV system is a collection of program modules operating on a unified data base (UDB) designed to facilitate finite element analysis using modern data management techniques. It is a significant improvement over its predecessor, GIFTS-II .

ORNL participated in the meeting organized by Brookhaven National Laboratory on structural analysis needs in superconducting magnets. Five ORNL staff members from the Fusion Energy, Metals and Ceramics, and Engineering Divisions were present. W.C.T. Stoddart and W. H. Gray represented the Magnetics and Superconductivity Section. Sessions were chaired by C. R. Brinkman and W.C.T. Stoddart; Stoddart also presented an overview of the ORNL magnet structural analys is efforts.

The GFUN-3D computer program has been acquired from the Rutherford High Energy Laboratory in England. This computer program will perform a thiree-dimensional magnetostatic field analysis including the nonlinear effects due to ferromagnetic material. The code has been converted to account for the differences in the ORNL and Rutherford computational environment. C. W. Trowbridge and J. Simkin of Rutherford Laboratory assisted W. D. Cain in the implementation and check-out of this code. It is currently being used to calculate the influence of iron on the magnetic field of several electromechanical devices under design at $\mathrm{ORNL}$. 
D. L. Levine and W. H. Gray modified the STANSON-I I $^{3}$ computer program to augment the output with a sequence of computer plots which present the computed values in a concise form. The augmented version of the code is referred to as STANSOL-IIP (LOT). To facilitate the use of STANSOL-IIP (or -II), a preprocessor code, STNDAT, was also developed. This code interactively accepts input data about the geometry, material properties, and electrical characteristics of a solenoid and creates an input data file in a format acceptable to STANSOL $=$ IIP.

These codes were extensively used during the EBT-II design studies discussed elsewhere in this report. Also, structural analys is and design guidance were provided for the LCS, LCP, TNS, ISX, and ORMAK Upgrade projects.

Our interest in graphical representation of the voluminous input and output data required and produced during magnetic and structural analysis has led to the modification of several graphic software libraries. These libraries, LSLTEK, LSLVEC, VECTEK, CALVEC, CALDD8, DISVEC, and DISDD8, are used routinely by users of the FED PDP-10. The last two programs represent the most important contribution, as they are the back end to the display graphics package.

Electromechanical Stress Analys is of Transversely Isotropic Solenoids. ${ }^{34}$ W. H.

Gray and J. K. Ballou. The mechanical behavior of superconducting magnets deviates from isotropy due to their construction techniques, which involve layering superconductor, insuiation, and sometimes structural reinforcement within the windings. Previous mechanical analyses considered the windings of a magnet to behave isotropically. This paper describes an analytical solution for deflection, stress, and strain of axisymmetric, electromechanically loaded, and rotationally transversely isotropic solenoids. The results indicate that for magnets with a large radial build compared to inner radius, transverse isotropy has a dramatic effect; for magnets with a small radial build compared to inner radius, transverse isotropy has a negligible effect.
Photoelastic Analysis of Stresses in Toroidal Magnetic Field Coils. ${ }^{35} \mathrm{H}$. Pih. Several two-dimensional photoelastic stress analyses were made on models of circular and oval toroidal magnetic field coils for fusion reactors. The circumferential variation of each coil's in-plane magnetic force has been simulated by applying different pressures to 16 segmented regions of the inner surface of the models. One special loading fixture was used for the model of each shape and size. Birefringence and isoclinic angles were measured in a transmission polariscope at selected points on the loaded model. Boundary stresses in the cases of known boundary cunditions were determined directly from the isochromatics. Separate principal stresses were calculated using the combination of photoelastic information and isopachic data obtained by the electrical analogy method from the solution of Laplace's equation. Comparisons were made between experimental results and those computed using the finite element method. The theoretical and experimental stress distributions agree very well, although the finite element method yielded slightly higher stresses than the phutuelastic method; further work is needed to resolve this difference. In this investigation several variations of coil geometry and several methods of support were evaluated. Based on experimental results, optimum structural designs of toroidal field coils were recommended.

Experience in the Use of Static SAP to Structurally Analyze Electromechanical Systems. ${ }^{36}$ W. D. Cain and W.C.T. Stoddart. A large-scale effort is presently being undertaken to design and construct large electrumechanical systems for use in controlled thermonuclear research machines; energy storage dcvices, and related systems. One of the major thrusts of this effort is directed toward the evaluation of stresses and deformations in toroidal field coils which are induced by electromagnetic body forces, differential temperatures, winding preloads, and other forces. The purpose of this paper is to describe some of the work which has transpired in the Fusion Energy and Engineering Divisions of Oak Ridge National Laboratory in 
the area of structural analysis of toroidal field coils. Basically, this paper describes the tools which have been developed to aid in the structural design analys is of electromechanical systems (in particular, TF coils l and relates some of the experiences encountered in the utilization and implementation of these tools.

Finite Element Calculation of StressInduced Heating of Superconductors. ${ }^{37} \mathrm{~J}$. E. Akin and A. Moazed. This research is concerned with the calculation of the amount of heat generated due to the development of mechanical stresses in superconducting composites. An empirical equation is used to define the amount of stress-induced heat generation per unit volume. The equation relates the maximum applied stress and the experimentally measured hysteresis loop of the composite stress-strain diagram. It is utilized in a finite element program to calculate the total induced heat generation for the superconductor. An example analysis of a solenoid indicates that the stressinduced heating can be of the same order of magnitude as eddy current effects.

\section{Materials evaluation}

The materials evaluation portion of the SCMDP concerns itseif with the properties of all materials except the conductor. The bulk of the effort has been directed at metallic primary structural materials (design studies) and at organics for both electrical insulation and potting applications (experimental work).

The primary structure work, which involved extensive liaison with other parts of the SCMDP, ORNL, and the ERDA fusion community, has been summarized in a technical memorandum. ${ }^{38}$ C. J. Long was appointed secretary of an ERDA-DMFE Task Group on Special Purpose Materials for fusion reactors and continued as a member of ASTM-ASME-MPC Joint Committee Jl.06, Low-Temperature Effects on Materials Properties.

During 1976 a series of tests of mechanical properties was conducted at room and cryogenic temperatures on potential insulation systems and potting compounds by $k$. J. Froelich (who left
ORNL in September) and C. M. Fitzpatrick. A report on the results of tensile tests of insulators is in preparation.

A program to measure the radiation resistance of electrical insulators in liquid helium was formulated by C. J. Long (now Metals and Ceramics Division) and R. H. Kernohan (Solid State Division). This program, which will be conducted in the Low Temperature Irradiation Facility at the Oak Ridge Bulk Shielding Reactor, will measure degradation of both mechanical and electrical properties beginning in 1977.

A final report entitled "A Review of Electrical Insulation in Superconducting Magnets for Fusion Reactors" was prepared for ORNL by Magnetic Engineering Associates. The report concludes that significant radiation damage might be expected in organic insulators in a fusion reactor during its 1 ifetime.. No appreciable damage is expected in inorganic insulators.

Structural Materials for Large Superconducting Magnets for Tokamaks. ${ }^{39}$ C. J. Long. The selection of structural materials for large superconducting magnets for tokamak fusion reactors is considered. The important criteria are working stress, radiation resistance, electromagnetic interaction, and general feasibility. The most advantageous materials appear to be face-centered-cubic alloys in the $\mathrm{Fe}-\mathrm{Ni}-\mathrm{Cr}$ system, but high-modulus composites may be neçessary when severe pulsed magnetic fields are present. Special purpose structural materials are considered briefly.

Lap Shear Strength of Selected Adhesives (Epoxy, Varnish, B-Stage Glass Cloth) in Liquid Nitrogen and at Room Temperature. $40 \mathrm{~K}$. $\mathrm{J}$. Froelich and C. M. Fitzpatrick. The lap shear strengths of several adhesives were measured in liquid nitrogen and at room temperature. The adhesives included several epoxy resins, a varnish, and a B-stage glass cloth (a partially cured resin in a fiberglass cloth matrix). Several parameters critical to bond strength were varied: adhesive and adherend differences, surface preparation, coupling agents, epoxy thickness, fillers, and bonding pressure and 
temperature. The highest lap shear strengths were obtained with B-stage glass cloth at both liquid nitrogen and room temperatures with values of approximately $20 \mathrm{MPa}(3000 \mathrm{psi})$ and $25.5 \mathrm{MPa}(3700 \mathrm{psi})$, respectively.

\section{4 .3 Fabrication Development}

A large coil winding facility was constructed in the $\mathrm{Y}-12 \mathrm{Pl}$ ant Electric Shop. Preliminary shakedown winding using a round bobbin was carried out and the operating characteristics of the winding equipment were evaluated. Some additions and refinements have since been made in the equipment. A variable speed motor drive and controls have been procured for the winding table. Elevating mechanisms have been installed on both the tensioner and dereeler. Extensive alterations in the drive and controls of the dereeler have been made. Also, a prototype automatic winding clamp for keeping the windings compressed is in the shop and near completion. Before any practice winding could be done with the revised equipment it was necessary to relocate from the $\mathrm{Y}-12 \mathrm{Plant}$ Electric Shop to Building 9201-4. An oval bobbin is now available for practical winding; it will help identify problem areas associated with fabricating LCP coils. The equipment will be used to wind the 1 arge coil segments.

The coil fabricating laboratory in Building 9204-1 now has equipment for winding coils up to $1.5 \mathrm{~m}$ in diameter. A very accurate tensioner (2\%) has been developed for maintaining a conductor tension of up to $100 \mathrm{~kg}$ while winding. Several small superconducting coils for the pulsed poloidal coil project have been wound using this equipment.

A novel method of winding fat toroidal coils was developed for the pulsed parallel field experiment. The winding is laced in and has no splices at all, a feature which is especially important in winding superconductors. Also, the major axis can be filled completely with conductors, thus obtaining the maximum possible number of ampere turns. These requirements cannot be met with industrial equipment. This method of lace winding may have applications in remote winding and unwinding (for example, of radiation damaged $P F$ coils in fusion reactors). For the pulsed parallel field experiment, an inner spool inside the toroidal coil can be rutated for winding and unwinding cunductor samples to be tested without disturbing the toroidal coil.

\subsection{PROJECTS REQUIRING WORK BY SUBCONTRACTORS}

\subsubsection{Furced-Cuoled Magnets ${ }^{*}$}

A study 41,42 was conducted that concluded that economic cooling systems of forced-cosled superconducting magnets must employ efficient cold pump recirculators in which the flow to the magnets is confined to the cold end of the refrigeration column. This holds true if the liquid pump efficiency is $40 \%$ or greater.

Tests have been performed and results reported ${ }^{4-45}$ measuring the stability of two types of forceed-flow-cooled NbTi filament conductors. The tests were successful in that they demonstrated experimental results to be equal to or better than theoretically predicted conductor behavior during a recovery from a localized quench. Test measurements included voltage drop, helium discharge temperature, and pressure drop across the coil. Triplex wire conductor proved superior to grooved wire. Testing will continue with a modified version of the triplex wire cable.

A 1-m-scale test of a racetrack coil of $\mathrm{NbTi}$ filament superconductor has been designed for operation late in 1977. Five kilometers of $\mathrm{NbTi}$ superconductor wire have been received and a contract for fabrication of the coil is being negotiated. Construction of the installation site at the Francis Bitter National Magnet Laboratory has started and component

\footnotetext{
*Subcontract with the Francis Bitter National Magnet Laboratory, MIT.
} 
parts of the test loop have been ordered. All components are expected for delivery by June 1977.

An additional contract to be supervised by ORNL has been signed with ERDA to evaluate the feasibility of $\mathrm{Nb}_{3} \mathrm{Sn}$ forced-flow conductors.

\subsubsection{Helium Refrigerator and Handling System}

Helium refrigerator and reliquefier

A contract has been awarded to purchase a helium reliquefier and refrigerator from Cryogenic Technology, Incorporated, Wal tham, Massachusetts. The refrigerator has the capacity to produce $0.0045 \mathrm{~kg} / \mathrm{sec}$ of 1 iquid helium and 866 W of refrigeration simultaneously at $3.56 \mathrm{~K}$ and $0.5 \mathrm{~atm}$. This refrigerator and the liquid helium system connected with it should have the capacity to supply helium coolant to the first phase of operation of the Large Coil Project.

The refrigerator has a two-stage, oillubricated, rotary-screw compressor. The low pressure stage is rated at $400 \mathrm{hp}$ and can operate with a $0.4-\mathrm{atm}$ suction $(0.5 \mathrm{~atm}$ at the return inlet to the coldbox). The high pressure stage has a $1000 \mathrm{hp}$ motor. The overall compression ratio is about 35 to 1 for the two stages. Delivery is expected by July 1, 1977 and operation by January 1, 1978.

\section{Liquid helium handling system}

Ihe iliquid hellum system assoclated with the refrigerator consists of an 18,000 liter (5000 gal) liquid hel ium storage dewar, a transfer line which will connect to the experiment and to the laboratory, helium gas storage capacity for an equivalent of 7200 liters of liquid, and gas Ines to and from the compressor. Additional storage of gas, when required, will be supported by portable helium tanks. Detailed design of the liquid helium handling system is being carried out by the Engineering Division with the assistance of a subcontract architect-engineer chosen by ERDA.
1.6 VISITORS (OCTOBER I TO. DECEMBER $31,1976^{*}$ )

Oct. 11-15 Jack Fivel, McDonnel Douglas

Oct. 19 Robert J. Koenig, Leinart A. Malewicz, GE, Schenectady, NY

0ct. 19 Saul Silverman, University of California

Oct. 21

Frank P. Falcone, Thomas W. Schuck, Gardner Cryogenics Division, Bethlehem, PA

oct. 28 Robert Botwin and Paul Butler, Grumman Aerospace

Nov. 11 John Wen-Hue-Chi, John $H$. Murphy, Joe Josiah Lynn Yang, Westinghouse

Nov. 19 Masayuki Nagati, Sumitomo Elec. Industries, Ltd.; Japan

Nov. 19 Eric Adam, Airco, Murray Hill, NJ

Nov. 24

Gary C. Guenther, Nat. Oceanic \& Aeronautics Ad, Washington, DC

Nov. 24

Charles S. Parmele Hydroscience, Inc., Knoxville

Nov. 24 E. Bertolini, Michel Huguet, Rudolf Dieter Pohlchen, Tullio Raimondi, Paul-Henri Rebut, Culham Lab, Engl and

Nov. 30 Keith H. Sueker, Robicon Corp.

Dec. $2-3$

Dec. 3 Mitch 0. Hoenig, MIT, NML Douglas A. Koop Clay $N$. Whetstone, Alcoa

Dec. 7 Eric A. Larson, W. A. Brown Instruments, Oak Ridge

Dec. 7 Ed Fisher, Ithaco, Inc., Ithaca, NY

Dec. 13 Wesley W. Craddock, University of Wisconsin

\footnotetext{
${ }^{\star}$ The three previous quarterly reports include lists of visitors during their respective periods; there is thus no need for duplication.
} 
1.7 STAFF TRIPS (OCTOBER 1 TO DECEMBER 31,1976 )

J. K. Ballou

November 3-5

J. F. Ellis

October 11-14

W. A. Fietz

November 8-10

December 7

vecertiber $y$

December 9

December 16-17

C. G. Lawson

November 3-4

November 5

C. J. Long

October 13

October 26-28

November $8-10$

M. S. Lube11

Sept. 26-0ct. 2

October 3-5

October 11

October 12-13

J. W. Lue

Dct, 7-Des, 3

November 4-5

December 9-14

J. N. Luton

November 12

December 13

J. R. Miller

November 8-10

December 10-11
EPR Meeting, University of Madison, WI

ISA-1976 International

Conference, Houston, TX

ASM Conference, Port

Chester, NY

MCA \& Supercon, Boston, MA

Ilic, Albäñy, NY

Airco, Murray Hill, NJ

Meeting, Washington, DC

BNL, Upton, $N Y$

MIT, NML

Meeting with ERDA \& NBS personnel, Washington, DC

Metals show, Cleveland, $\mathrm{OH}$

ASM Conference, Port

Ches Ler, NY

Moscow, U.S.S.R. (1 isted in September trips)

Leningrad

Saclay, France

Karlsruhe

\section{MIT}

IIniversit.y of Wisconnsin

MIT, NML

University of Wisconsin ERDA-DMFE

ASM Conference, Port Chester, NY MIT, NML
W.C.T. Stoddart

October 13

Washington, DC

P. L. Walstrom

October 11-14

ISA-1976 International

Conference, Houston, TX

October 15

Los Alamos

1. Abstract of ORNL/TM-5574, Oak Ridge National Laboratory, Oak Ridge, Tennessee (1976).

2. Nbstract of paper presented at the 1976 Applied Superconductivity Conference, Palo Alto, lalifornia, August $1 \%-20,19 / 6$.

3. D. G. McAlees, N. A. Uckan, E. S. Bettis, P. B. Burn, C. L. Hedrick, D. B. Nelson, R. T. Santoro, H. L. Watts, H. T. Yeh, L. M. Lidsky, D. A. Ehst, A. Pant, J. S. Herring, D. L. Kaplan, and R. E. Potok, "The ELMO Bumpy Torus Reactor," paper presented at the 2nd Topical Meeting on the Technology of Controlled Thermonuclear Fusion, Richland, Washington, September 21 23, 1976.

4. D. G. McAlees, N. A. Uckan, E. S. Bettis, P. B, Burn, , C. L. Hedrick, D. B. Nelson.

R. T. Santoro, H. L. Watts, H. T. Yeh, I.. M. Lidsky. D. A. Fhst, A. Pant., I. S. Herring, D. L. Kaplan, and R. E. Potok, The ELMO Bumpy Torus Reactor (EBTR) Reference Design, ORNL/TM-5669, Oak Ridge National Laboratory, Oak Ridge, Tennessee (November 1976)

5. L. Urésner, J. K. Miller, and L. W. Donaldson. "Propagation of Normal Zones in Composite Superconductors," paper presented at the 6th Symposium on Engineering Problems of Fusion Research, San Diegn, California, November 18-21, 1975.

6. Abstract of paper published in Cryogenics 16, 675 (1976); see also ORNL/TM-5543.

7. Abstract of paper presented at the 1976 Applied Superconductivity Conference, Palo Alto, California, August 17-20, 1976; see also ORNL/TM-5637.

8. Abstract of paper presented at the 1976 Applied Superconductivity Conference, 
Palo Alto, California, August 17-20, 1976; see also ORNL/TM-5637.

9. Abstract of paper presented at the 1976 Applied Superconductivity Conference, Palo Alto, California, August 17-20, 1976.

10. D. S. Easton and D. M. Kroeger, "Temperature Increases in Superconductivity Composites as a Result of Tensile Strain," Fall Meeting, AIME, Niagara Falls, New York, September 20-23, 1976.

11. D. S. Easton, "Stress Effects on the Current Densities of Commercial Conductors at 4.2. K in Magnetic Fields," paper presented at the 1976 Applied Superconductivity Conference, Palo Alto, California, August 17-20, 1976.

12. D. S. Easton, "Stress Effects on Mechanical and Superconducting. Properties of Commercial Conductors at $4.2 \mathrm{~K}$," paper presented at the 3rd NBS-ARPA Workshop, Vail, Colorado, April 5-6, 1976.

13. D. S. Easton, "The Effect on Critical Current of Tensile Stress in $\mathrm{Nb}_{3} \mathrm{Sn}$ and NbTi Superconducting Composites," paper presented at the Spring Meeting, AIME, Las Vegas, Nevada, February 22-26; 1976.

14. Abstract of paper published in Appl. Phys. Lett. 29, 319 (September 1976).

15. Abstract of paper published in Appl. Phys. Lett. 29, 382 (September 1976).

16. Abstract of paper presented at the 1976 Applied Superconductivity Conference, Palo Alto, California, August 17-20, 1976.

17. W. H. Gray et al., Papers on ac Losses and Pulsed Coils Submitted to the Applied Superconductivity Conference, ORNL/TM-5635, Oak Ridge National Laboratory, Oak Ridge, Tennessee (August 1976).

18. Abstract of paper presented at the 1976 Applied Superconductivity Conference, Palo Alto, California, August 17-20, 1976; see also ORNL/TM-5635.

19. Abstract of paper presented at the 1976 Applied Superconductivity Conference, Palo Al to, California, August 17-20, 1976; see also ORNL/TM-5635.
20. H. T. Yeh and J. W. Lue, The Interaction and Protection of Superconducting Poloidal Field coils and Tonoidal Field coils in a Tokamak EPR, ORNL/TM-5542, Oak Ridge National Laboratory, Oak Ridge, Tennessee (September 1976).

21. Abstract of paper presented at the 1976 Applied Superconductivity Conference, Palo Alto, California, August 17-20, 1976; see also ORNL/TM-5635.

22. Abstract of paper presented at the 2nd ANS Topical Meeting on the Technology of Controlled Thermonuclear Fusion, Richland, Washington, September 21-23, 1976; see also ORNL/TM-5661.

23. Abstract of paper presented at the 1976 Applied Superconductivity Conference, $\mathrm{Pa} 10$ A1to, California, August 17-20, 1976; see a) So ORNL/TM-5635.

24. Abstract of paper to be published in Rev. Sci. Instrum.

25. Paper submitted at the ISA International Conference and Exhibit, Houston, Texas, October 11-14, 1976.

26. Paper submitted at the ISA International Conference and Exhibit, Houston, Texas, October 11-14, 1976; see ORNL/TM-5596.

27. S. S. Shen and H. T. Yeh, "Pulse Loss and Voltage Measurements on Superconducting Magnets," paper presented at the 1976 Applied Superconductivity Conference, Palo Alto, California, August 17-20, 1976; see also ORNL/TM-5635, Oak Ridge National Laboratory, Oak Ridge, Ténnessee (December 1976).

28. Abstract of ORNL/TM-5542, Oak Ridge National Laboratory, Oak Ridge, Tennessee (September 1976).

29. Abstract of ORNL/TM-5333, Oak Ridge National Laboratory, Oak Ridge, Tennessee (June 1976).

30. Abstract of ORNL/TM-5652, Oak Ridge National Laboratory, Oak Ridge, Tennessee (December 1976).

31. Abstract of ORNL/TM-5652, Oak Ridge National Laboratory, Oak Ridge, Tennessee 
(December 1976).

32. Abstract of ORNL/CSD/TM-18, Oak Ridge National Laboratory, Oak Ridge, Tennessee (November 1976).

33. N. E. Johnson, W. H. Gray, and R. A. Weed, "Stress Analysis of Non-Homogeneous, Transversely Isotropic Superconducting Solenoids," paper presented at the 6 th Symposium on Engineering Problems of Fusion Research, San Diego, California, November 18-21, 1975.

34. Abstract of paper accepted for publication in J. Appl. Phys., 1976.

35. Abstract of ORNL/TM-5724, 0ak Ridge National Laboratory, Uak Ridge, Tennessee (February 1977).

36. Abstract of paper presented at the 1st SAP User's Conference, University of Southern California, Los Angeles, California, June 6-11, 1976.

37. Abstract of paper presented at the 1976 Applied Superconductivity Conference, Palo Al.to, California, August 17-20, 1976; see al so ORNL/TM-5635.

38. C. J. Long, ORNL/TM-5632, Oak Ridge National Laboratory, Oak RIdge, Tennessee (December 1976).

39. Abstract of ORNL/TM-5632, Oak Ridge National Laboratory, Oak Ridge, Tennessee (Uecemlue, 1970).

40. Abstract of ORNL/TM-5658, Oak Ridge
National Laboratory, Oak Ridge, Tennessee (1976).

41. Adrian Bejan, "Refrigeration for ForcedCooled Large Superconducting Magnets," paper presented at the ASME National Meeting, New York, New York, December 1215, 1976.

42. Adrain Bejan and M. 0. Hoenig, "Refrigeration Costs for Forced-Cooled Superconducting Magnets," paper presented at the 1976 Applied Superconductivity Conference, Palo Alto, California, August 17-20, 1976.

43. M. O. Hoenig, Y. Iwasa, D. B. Montgomery, and A. Bejan, "Supercritical Helium Cooled, Cabled, Superconducting Hollow Conductors for Large lligh Field Magnets," Paper I-9, presented at the International Cryogenics Engineering Conference, Grenoble, France, April 1976.

44. Y. Iwasa, M. J. Lupold, J.E.C. Williams, "Stabilization of Large Superconducting Magnets: Experimental Models," paper presented at the 1976 Applied Superconductivity Conference, Palo Alto, California, August 17-20, 1976.

45. Y. Iwasa, M. O. Hoenig, and D. B. Montgomery, "Cryostability of a Small Superconducting Coil Wound with Cabled Hollow Conductor," paper presented at the 1976 Applied Supceconductivity Confepence, Palo Alto, California, August 17-20, 1976. 
INTERNAL DISTRIBUTION

1. J. K. Ballou

2. R. L. Brown

3. E. H. Bryant

4. P. B. Burn

5. W. D. Cain

6. D. D. Cannon

7. J. F. Clarke

8. F. L. Culler

9. L. Dresner

10. J. F. Ellis

11. W. A. Fietz

12. W. H. Gray

13. P. N. Haubenreich

14. J. P. Kois

15. G. G. Kelley

16. G. A. Krist

17. C. G. Lawson

18. C. J. Long

i9. H. M. Long

20. J. K. Lovin

27-30. M. S. Lubell

31. J. W. Lue

32. J. N. Luton

33. H. C. McCurdy

34. J. R. Miller
35. R. V. Miskell

36. 0. B. Morgan

37. L. W. Nelms

38. H. Pih

39.' H. Postma

40. M. Roberts

41. M. W. Rosenthal

42. R. E. Schwall

43. T. E. Shannon

44. S. S. Shen

45. J. E. Simpkins

46. D. Steiner

47. W. C. T. Stoddart

48. P. B. Thompson

49. P. L. Waistrom

50. H. T. Yeh

51. A. Zucker

52-53. Central Research Library

54. Fusion Energy Division Reports Office

55. Document Reference Section

56-57. Laboratory Records Department

58. Laboratory Records - ORNL RC

59. ORNL Patent Office

60-61. Fusion Energy Division Library

\section{EXTERNAL DISTRIBUTION}

62. E. Adam, Airco, 100 Mountain Avenue, Murray Hill, NJ 07974

63. V. D. Arp, National Bureau of Standards, Boulder, CO 80302

64. J. W. Beal, Division of Magnetic Fusion Energy, ERDA, Mail Stop G-234, Washington, OC 20545

65. R. W. Boom, 513 Engineering Research Building, University of Wisconsin, Madison, WI 53706

66. A. Clark, National Bureau of Standards, Boulder, CO 8030 ?

67. D. L. Coffey, American Magnetics Inc., P.0. Box R, Oak Ridge, TN 37830

68. W. Coles, NASA Louis Research Laboratory, Cleveland, $\mathrm{OH} 44108$

69. D. N. Comish, Lawrence Livermore Laboratory, P.0. Box 808, Livermore, CA 94550

70. M. D'Agostino, Gruman Aerospace Corporation, Bethpage, NY 11714

71. R. W. Derby, Magnetics Engineering Associates, 247 Third Street, Cambridge, MA 02141

72. D. A. Dingee, Manager, Fusion Programs, Battelle-Northwest, Battelle Boulevard, Richland, WA 99352

73. Director, Research and Technical Support Division, ERDA, Oak Ridge Operations, Oak Ridge, TN 37830

74. R. W. Fast, Manager, Experimental Facilities, National Accelerator Laboratory, P.0. Box 500, Batavia, IL 60510 
75. J. J. Ferrante, General Electric Co., Schenectady, NY 12345

76. F. Fickett, National Bureau of Standards, Boulder, CO 80302

77. J. File, Princeton University, Plasma Physics Laboratory, Princeton, NJ 08540

78. H. K. Forsen, Laser Enrichment Department, Exxon Nuclear Co., Inc., 777-106th Avenue, NE, C-00777, Bellevue, WA 98009

79. H. P. Furth, Princeton University, Plasma Physics Laboratory, Princeton, NJ 08540

80. W. S. Gilbert, Lawrence Berkeley Laboratory, University of Callfornia, Berkeley, CA 94120

81. R. W. Gould, Department of Applied Physics, California Institute of Technology, Pasadena, CA 91109

82. E. Gregory, Airco, 100 Mountain Avenue, Murray Hi11, NJ 07974

83. D. S. Hackley, General Dynamics, Convair Division, P.0. Box 80847, San Diego, CA 92138

84. W. V. Hassenzah1, Los Alamns Scientific Laboratory, P.0. Box 1663, Los Alamos, NM 87544

85. C. D. Henning, Division of Magnetic Fusion Energy, ERDA, Mail Stop G-234, Washington, DC 20545

86. G. K. Hess, Division of Magnetic Fusion Energy, ERDA, Mail Stop G-234, Washington, DC 20545

87. M. O. Hoenig, Massachusetts Institute of Technology, National Magnet Laboratory, 170 Albany Street, Cambridge, MA 02139

88. C. K. Jones, Manager, Cryogenic Research Laboratory, Westinghouse Electric Corporation, Research and Development Center, Pittsburgh, PA 15235

89. E. E. Kintner, Division of Magnetic Fusion Energy, ERDA, Mai] Stop G-234, Washington, DC 20545

90. H. L. Laquer, Los Alamos Scientific Laboratory, P.0. Box 1663, Los Alamos, NM 87544

91. C. Laverick, 543 Hampshire Lane, Boling Brook, IL 60439

92. D. B. Montgomery, Massachusetts Institute of Technology, National Magnet Laboratory, 170 Albany Street, Cambridge, MA 02139

93. F. Moon, Department of Theoretical and Applied Mechanics, Cornell University, Ithaca, NY 14850

94. C. Oberly, Aero Propulsion Laboratory, Power Distribution Branch, Wright-Patterson Air Force Base, $\dot{\mathrm{OH}}, 45433$

95. J. R. Powel], Brookhaven National Laboratory, Upton, NY 11973

96. J. R. Purcel1, General Atomic Company, P.0. Box 81608, San Diego, CA 92138

y/. P. Keardon, Princeton Plasma Physics Laboratory, Princeton University, P.0. Box 45ī, Princeton, NJ U⿺辶540

98. R. P. Reed, National Bureau of Standards, Boulder, C0 80302

99. J. D. Rogers, Q-26, Los Alamos Scientific Laboratory, P.0. Box 1663, Los Alamos, NM. 87544

100. D. J. Rose, Department of Nuclear Engineering, Massachusetts Institute of Technoloqy, Cạmbridqe, Mn 02139

101. C. H. Rosner, Intermagnetics General Corporation, Charles Industrial Park, New Karner Road, Gui Ideriand, NY lzU84

102. W. B. Sampson, Brookhaven National Laboratory, Upton, Long Island, NY 11973

103. S. St. Lorant, Stanford Linear Accelerator Center, Sand Hill Road, Palo Alto, CA 94304

104. Z. J. J. Stekly, Magnetic Corporation of America, 179 Bear Hill Road, Waltham, MA 02154

105. L. D. Stewart, Princeton Plasma Physics Laboratory, Princeton University, P.0. Box 451, Princeton, NJ 08540

106. B. P. Strauss, Fermi National Accelerator Laboratory, P.0. Box 500, Batavia, IL 60510

107. C. E. Taylör, Lawrence Livermore Laboratory, P.U. Box 808, L-384, Livermore, CA 94551

108. R. Thomas, General Atomic Company, P.0. Box 81608, San Diego, CA 92138

109. C. von Keszycki, Grumman Aerospace Corporation, Research Center, Building 26, Bethpage, NY 11714 
110. S. T. Wang, Argonne National Laboratory, 9700 South Cass Avenue, Argonne, IL 60439

111. J. P. Waszczak, Manager, Energy Programs, General Dynamics, Convair Division, P.0. Box 80847, San Diego, CA 92138

112. J. M. Williams, Division of Magnetic Fusion Energy, ERDA, Mail Stop G-234, Washington, DC 20545

113. S. L. Wipf, Q-26, Los Alamos Scientific Research Laboratory, P.0. Box 1663, Los Al amos, NM 87544

114. W. W. Withee, Director, Energy Systems, General Dynamics, Convair Division, P.0. Box .80847, San Diego, CA 92138

115. J. Wong, Supercon, Incorporated, 9 Erie Drive, Natick, MA 01760

116. H. H. Woodson, Chairman, Department of Electrical Engineering, University of Texas, Austin, TX 78712

117. J. L. Young, Westinghouse Electric Corporation, P.0. Box 10864, Pittsburgh, PA 15236

118. E. J. Ziurys, Division of Magnetic Fusion Energy, ERDA, Mail Stop G-234, Washington, DC 20545

119. Dr. Y. Aiyama, Electrotechnical Laboratory, 5-4-1 Mukodai-cho, Tanashi-City, Tokyo, Japan

120. Dr. Gunther Bogner, Forschungslaboratorien, Siemens Aktienge Sellshaft, Postfach 325, D8520 Erlanger 2, West Germany

121. Dr. Gaston Bronca, Department du Synchrotron Saturne, CEN/Saclay, F91 190, Gif-sur-Yvette, France

122. Dr. Henri Desportes, STIPE, CEN/Saclay, F91190, Gif-sur-Yvette, France

123. Professor G. W. Donaldson, School of Electrical Engineering, University of New South Wales, P.0. Box 1, Kensington, New South Wales 2033, Australia

124. Dr. Yoshio Furuto, Chief of Superconducting Group, Central Research Laboratory, Furukawa Electric Company, Ltd., 9-15, 2-Chome, Futaba, Shinagawa-ku, Tokyo 141, Japan

125. Prof. Dr. W. F. Gauster, c/o, o. Professor Dr. techn. H. Kirchmayr, Director, Institut für Experimentalphysik, der Technischen Hochschule in Wien, A-1040 Vienna, Karlsplatz 13, Austria

126. Dr. Roger Hancox, UKAEA, Culham Laboratory, Abingdon, OXON, OXI4-3DB, Engl and

127. Professor W. Heinz, Gesellschaft für Kernforschung, Institut für Experimental Kernphysik, 75 Karls ruhe, Postfach 3640 , West Cermany

128. Toru Hiraoka, Japan Atomic Energy Research Institute, Tokai Research Establishment, Tokai-Mura, Naka-Gun, Ibaraki-Ken, Japan

129. Dr. Seijiro Ihara, Energy Division, Electrotechnical Laboratory, 5-4-1 Mukodai-cho, Tanashi-City, Tokyo, Japan

130. Dr. Masatami Iwamoto, Central Research Laboratory, Mitsubishi Electric Corporation, 80 Nakano, M1 nainitshiurtzu, Amagasak1, Hyogo Prefecture, Jàäăn b6U

131. Dr. T. Kasahara, Hitachi Works, 3-1-1 Saiwai-cho, Hitachi-shi, Ibaraki-ken 317, Japan

132. Dr. Alfred A. Koch, Brown, Boveri and Company, Itenhard 29, CH-5620 Bremgarten, CH-8050 Zurich, Bade, Switzerland

133. Dr. Albert Knobloch, Max-Planck Institut für Plasmaphysik, Abteilung Technik, 8046 Garching bei Munich, West Germany

134. Dr. Peter Komarek, Institut für Experimental Kernphysik, 75 Karlsruhe, Postfach 3640, West Germany

135. Dr. Kenịchi Koyama, Electrotechnical Laboratory, 5-4-1 Mukodai-cho, Tanashi-City, Tokyo, Japan

136. Ur. Kunishige Kuroda, Hitachi, Ltd., lentra1 Research Laboratory, 1-280, Higa Shiko İgakubo, Kokubumji, Tokyo 185, Japan

137. Dr. Alberto Martinel1i, DSS SEDAP, B.P. No. 2, CEN/Saclay, F91190, Gif-sur-Yvette, France

138. Max-Planck Institut für Plasmaphysik, 8046 Garching bei München, Federal Republic of Germany 
139. Dr. Masao Nozawa, Japan Atomic Energy Research Institute, Tokai Research Establishment, Tokaimura, Naka-gun, Ibaraki-ken, Japan

140. Professor T. Ogasawara, Department of Physics, College of Science and Engineering, Nihon University, Kanada-Surugadai, Chiyoda-ku, Tokyo, Japan

141. Dr. H. Ogiwara, Toshiba Research and Development Center, 1 Komukai Tsohibacho, Saiwai-ku, Kawasaki-City, Kanagawa 210, Japan

142. Dr. Jacques Parain, CEN/Saclay, B.P. No. 2, F91190 Gif-sur-Yvette, France

143. Dr. G. Sacerdoti, Laboratoroi Nazionali, Cas. Postale 70, 00044 Frascati, Italy

144. Dr. Yoshio Sawada, Manager of Advanced Engineering Group, Heavy Apparatus Engineering Laboratory, Tokyo Shibaura Electric Co., Ltd. 4, 2-Chome, Suehiro-cho, Tsurumi-ku, Yokama, Japan

145. Director K. Schmitter, Max-Hlanck Instituit für Plasmaphys1k, 8048 Garchlny bei Murich, West lermany

146. Dr. S. Shimamoto, Japan Atomic Energy Research Institute, Toka1 Research Establishment, Tokaimura, Naka-gun, Ibaraki-ken, Japan

147. Dr. M. Spadoni, Laboratori Nazionali, Cas. Postale 70, 00044 Frascati, Italy

148. Dr. Kyoji Tachikawa, Chief of Electric Materials Laboratory, National Research Institute for Metals, 3-12, 2-Chome, Nakameguro, Meguru-ku, Tokyo, Japan

149. Professor D. T. Uchida, Nuclear Engineering Department, University of Tokyo, Tokyo, Japan

150. Dr. Colin Walters, Technology Division, Building R25, Rutherford Laboratory, Chilton, Didcot, Oxfordshire, $0 \times 1100 x$, England

151. Dr. M. Yamamoto, Toshiba, Tsurumi Works, 4, Suehiro-choizchome, Tsurumi-ku, Yokohama, 230, Japan

152. Professor Ko Yasukochi, Dept. of Physics, College of Science and Engineering, Nihon Univerșity, Kanada-Surugadai, Chiyoda-ku, Tokyo, Japan

153-179. Technical Information Center, P.0. Box 62, Oak Ridge, TN 37830 